\title{
CHOROBY UKŁADU SERCOWO-NACZYNIOWEGO - DZIAŁANIA PROFILAKTYCZNE I EDUKACYJNE W RAMACH POWIATOWEGO PROGRAMU PROFILAKTYKI I PREWENCJI ZDROWIA „RAZEM DLA SERCA” WŚRÓD MIESZKAŃCÓW POWIATU BIALSKIEGO
}

\author{
DISEASES OF THE CARDIOVASCULAR SYSTEM - PREVENTIVE AND \\ EDUCATIONAL ACTIVITIES WITHIN THE COUNTY PROGRAM OF PROPHYLAXIS \\ AND PREVENTION OF HEALTH “TOGETHER FOR THE HEART” AMONG THE \\ INHABITANTS OF THE BIAŁA PODLASKA COUNTY
}

\author{
Anna Ślifirczyk $\mathbf{k}^{1 \mathrm{~A}, \mathrm{~B}, \mathrm{C}, \mathrm{D}, \mathrm{E}, \mathrm{F}, \mathrm{G})}$ \\ ${ }^{1}$ Państwowa Szkoła Wyższa im Papieża Jana Pawła II w Białej Podlaskiej
}

\begin{abstract}
Ślifirczyk, A. (2018). Choroby układu sercowo-naczyniowego - działania profilaktyczne i edukacyjne w ramach powiatowego programu profilaktyki i prewencji zdrowia „Razem dla serca” wśród mieszkańców powiatu bialskiego. Rozprawy Społeczne, 12(4), 75-80. https://doi.org/10.29316/rs.2018.39
\end{abstract}

Wkład autorów:

A. Zaplanowanie badań

B. Zebranie danych

C. Dane - analiza i statystyki

D. Interpretacja danych

E. Przygotowanie artykułu

F. Wyszukiwanie i analiza

literatury

G. Zebranie funduszy

\begin{abstract}
Streszczenie
Wstęp. Choroby układu krążenia są najczęstszą przyczyną zgonów na świecie. Zmniejszenie poziomu tych czynników minimalizuje prawdopodobieństwo zachorowania, natomiast u chorych powoduje łagodniejszy przebieg dolegliwości i mniej powikłań (Kosobudzki, Bortkiewicz, 2012).

Materiał i metody. Program profilaktyczny przeprowadzono wśród 2500 osób w wieku 40-60 lat z wysokim ryzykiem zachorowania na choroby układu krążenia. Do badań zakwalifikowano 1325 kobiet i 1175 mężczyzn. Wykorzystano kartę badania profilaktycznego składającą się z trzech etapów (pytania metryczkowe, badania obrazowe i analityczne oraz ankieta ewaluacyjna).

Wyniki. U 76\% osób biorących udział w projekcie potwierdzono wystąpienie zawału i udaru w rodzinie. Podejmowanie aktywności fizycznej potwierdziło jedynie $22 \%$ badanych. Niestety, aż 88,39\% badanych mieszkańców powiatu bialskiego posiadało wskaźnik BMI mieszczący się w przedziale równym bądź przewyższający wartość 25 . Badania analityczne wśród $88 \%$ badanych uznane zostały przez lekarzy za nieprawidłowe. Stosując algorytm SCORE blisko 60\% osób poddanych badaniu zakwalifikowano do kategorii umiarkowanego ryzyka sercowo-naczyniowego.

Wnioski. Zbadano, iż blisko $60 \%$ osób biorących udział w projekcie znajdowało się w umiarkowanej grupie ryzyka zgonu z powodu incydentu sercowo-naczyniowego. Najczęstszym zaleceniem lekarzy pracujących w poradniach POZ była kontrola w poradni kardiologicznej. Zalecenie to dotyczyło ponad $27 \%$ ogółu badanych.
\end{abstract}

Słowa kluczowe: choroby układu krążenia, SCORE, profilaktyka

\section{Summary}

Introduction. Cardiovascular diseases are the most common cause of death in the world. The reduction of those risk factors minimizes the probability of disease, while in ill patients it causes a milder course of ailments and fewer complications (Kosobudzki, Bortkiewicz, 2012).

Material and methods. The preventive program was conducted among 2500 people aged 4060 with a high risk of developing cardiovascular disease. 1325 women and 1175 men were qualified for the study. A prophylactic examination card consisting of three stages was used (metrics questions, image and analytical tests, and an evaluation questionnaire).

Results. $76 \%$ of people participating in the project confirmed the occurrence of heart attack and stroke in the family. Physical activity was confirmed only by $22 \%$ of respondents. Unfortunately, as much as $88.39 \%$ of the surveyed inhabitants of the Biała Podlaska County had BMI index in the range equal to or above the value of 25 . Analytical studies among $88 \%$ of respondents were considered as being incorrect by the doctors. Using the SCORE algorithm, nearly $60 \%$ of subjects were classified to the category of moderate cardiovascular risk.

Conclusions. It was examined that nearly $60 \%$ of people participating in the project were in a group of moderate risk of death due to a cardiovascular incident. The control in cardiology clinics was the most frequent recommendation from doctors working in outpatient counselling centres. This recommendation related to more than $27 \%$ of all respondents.

Keywords: cardiovascular diseases, SCORE, prophylaxis
Ryciny: 10

Literatura: 20

Otrzymano: czerwiec 2017

Zaakceptowano: maj 2018

Adres korespondencyjny: Anna Ślifirczyk, Państwowa Szkoła Wyższa im Papieża Jana Pawła II w Białej Podlaskiej, ul. Sidorska 102, 21-500 Biała Podlaska, e-mail: aslifirczyk1@gmail.com, tel.: 833449900 , ORCID: https://orcid.org/0000-0002-2495-025X Copyright by: Państwowa Szkoła Wyższa im. Papieża Jana Pawła II w Białej Podlaskiej, Anna Ślifirczyk 


\section{Wstęp}

Choroby układu krążenia to aktualnie jeden z głównych powodów hospitalizacji czy niezdolności do pracy a także dużej liczby zgonów (Conroy, Pyorala, Fitzgerald, 2003). (Rodriguez-leyva, Mccullough, Pierce, 2009). Według Światowej Organizacji Zdrowia co roku z powodu chorób układu krążenia umiera ponad 17,3 miliona ludzi. Wprawdzie w ostatnich latach zapadalność na choroby układu krążenia zaczęła maleć, szacuje się, iż w XXI wieku wciąż będą one najpoważniejszym i najpowszechniejszym problemem zdrowotnym na świecie. Choroby układu krążenia to przyczyna ok. 50\% ogółu zgonów i są one głównym zagrożeniem zdrowia Polaków. Powszechnie wiadomo, że etiologia chorób układu krążenia jest złożona, a ich pojawienie się i rozwój powiązane są zarazem z klasycznymi czynnikami ryzyka (wysoki poziom cholesterolu, cukrzyca, otyłość, nadciśnienie tętnicze, brak aktywności fizycznej, a także niewłaściwa dieta czy palenie tytoniu), jak i środowiskowymi czy zawodowymi (Kosobudzki, Bortkiewicz, 2012; Korzeniowska-Ginter, Komorowska-Szczepańska, Stasiak-Szelągiewicz, 2013)

Choroby układu krążenia takie jak: udar mózgu, zawał serca, a także choroba wieńcowa, powstają na skutek działania wyżej wymienionych czynników ryzyka. W szczególny sposób narażone są te osoby, u których możemy zaobserwować jednocześnie kilka takich czynników (Szczęch, Narkiewicz, 2008). W zakresie profilaktyki, a także terapii chorób układu krążenia, ocena całkowitego ryzyka sercowo-naczyniowego jest podstawą do prawidłowego postępowania (Perk, 2012; Zdrojewski, Jankowski, Hoffman, 2015)

Dzięki postępowi w dziedzinie kardiologii udało się znacznie obniżyć śmiertelność szpitalną ostrych zespołów wieńcowych do standardów wiodących krajów europejskich, zaś śmiertelność przedszpitalna stale utrzymuje się na bardzo wysokim poziomie. Natomiast śmiertelność z powodu udarów mózgu jest jedną z najwyższych w Europie (Puddu, Menotti, Tolonen, 2011)
Mimo wszystko w ostatnich latach dowiedziono, że pacjenci z dobrymi wynikami leczenia hiperlipidemii, nadciśnienia tętniczego i cukrzycy zostaja nadal w grupie o podwyższonym ryzyku epizodów sercowo - naczyniowych (Zdrojewski i in., 2015).

Cel pracy: przeprowadzenie ogólnej oceny ryzyka zagrożenia chorobami układu krążenia i podniesienie świadomości $\mathrm{w}$ zakresie profilaktyki u mieszkańców powiatu bialskiego (północna część województwa lubelskiego).

\section{Materiał i metody}

W wyniku realizacji projektu został przeprowadzony program profilaktyczny „Razem dla serca” wśród wybranej grupy 2500 osób wysokiego ryzyka w wieku 40-60 lat w celu wczesnego wykrycia chorób układu krażenia. Do badań zakwalifikowano 1325 kobiet i 1175 mężczyzn.

W etapie wstępnym osoby przystępujące do projektu wypełniały ankietę na temat informacji o czynnikach ryzyka chorób układu krążenia.

W etapie pogłębionym 2500 osób zostało zakwalifikowanych i w wyznaczonym terminie podanych kompleksowym badaniom specjalistycznym $\mathrm{w}$ kierunku wczesnego wykrywania chorób układu krążenia: pobranie krwi oraz moczu i przekazanie materiału do badań biochemicznych, tzw. pakiet kardiologiczny, tj. morfologia 3 DIFF, mocz- badanie ogólne, OB., glukoza, kwas moczowy, cholesterol HDL, cholesterol LDL, trójglicerydy, kreatynina, mocznik, elektrolity (sód, potas), ALAT, ASPAT; RTG klatki piersiowej; badanie EKG; echokardiografia; porada u lekarza kardiologa. Trzeci etap stanowiła ankieta ewaluacyjna.

\section{Wyniki}

Badaniem objęto osoby w wieku 40-60 lat. Biorąc pod uwagę strukturę wieku, najliczniej reprezentowana była grupa osób w wieku 56-60 lat (29,39\%). Na drugim miejscu znalazły się osoby w wieku 5155 lat $(26,23 \%)$. Pozostałe grupy wiekowe uzyskały niewiele mniejsze wskaźniki udziału w strukturze próby badawczej (ryc. 1).

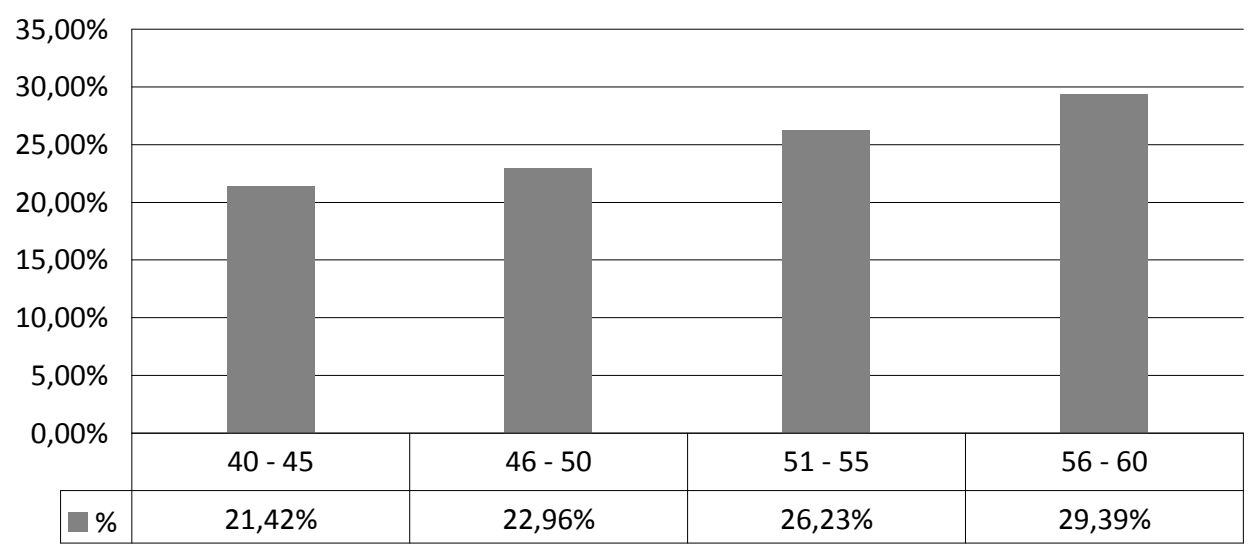

Rycina 1. Wiek badanych 
Istotnym czynnikiem ryzyka związanego z możliwością wystąpienia chorób układu krążenia okazało się być również posiadanie w rodzinie osób, wśród których wystąpiły zawały i udary. Aż 76\% osób biorących udział badaniu potwierdziło występowanie takich przypadków. Tym samym, tylko niecałe $1 / 3$ ogółu badanych nie posiada nikogo takiego w rodzinie (ryc. 2).

Podejmowanie aktywności fizycznej (np. spacery, marsze, bieganie, jazda na rowerze, pływanie, aerobik) rozumianej jako aktywność wykonywaną nie rzadziej niż 3 razy $w$ tygodniu po 30 minut potwierdziło jedynie $22 \%$ badanych. Wśród tych osób, średnia długość aktywności fizycznej (tygodniowo) wynosiła 201,5 minut (ryc. 3).

Niestety, aż 88,39\% badanych mieszkańców powiatu posiadało wskaźnik BMI mieszczący się w przedziale równym bądź przewyższającym wartość 25. Otyłość skrajna (BMI wynoszące 40 i więcej) dotyczyła 5\% ogółu badanych. Wskaźnik BMI w przypadku wielu mieszkańców okazał się czynnikiem ryzyka wystąpienia chorób układu krążenia (ryc. 4).
Kolejnym czynnikiem mogącym stanowić czynnik ryzyka wystąpienia chorób układu krążenia jest zdiagnozowana już wcześniej choroba tego układu. Aż 28\% badanych posiadała już wcześniej zdiagnozowane choroby układu krążenia (ryc. 5).

Łączna liczba czynników ryzyka z zakresu możliwości wystąpienia chorób układu krążenia w przypadku większości badanych wynosiła od 6 do 7 (54,73\%). Osoby u których zdiagnozowano od 4 do 5 czynników stanowiły $(37,91 \%)$. Na 7,12\% badanych przypadło od 8 do 9 czynników. Tym samym średnia liczba czynników przypadająca na badanego wynosiła 5,88 (ryc. 6).

Wskazanie do badań pogłębionych dotyczyło wszystkich (100\%) badanych.

Badania analityczne wśród 88\% badanych uznane zostały przez lekarzy za nieprawidłowe. W większości przypadków wskazywano nieprawidłowy poziom cholesterolu i glukozy (ryc. 7).

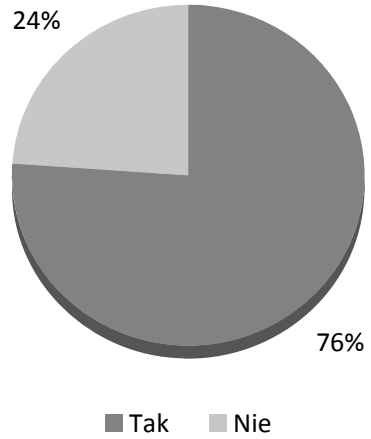

Rycina 2. Czy w rodzinie badanego wystąpiły zawały i udary?

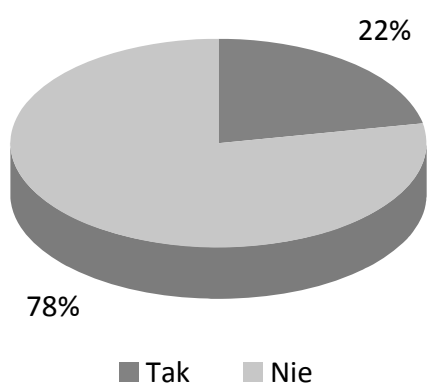

Rycina 3. Czy badany podejmuje aktywność fizyczną?

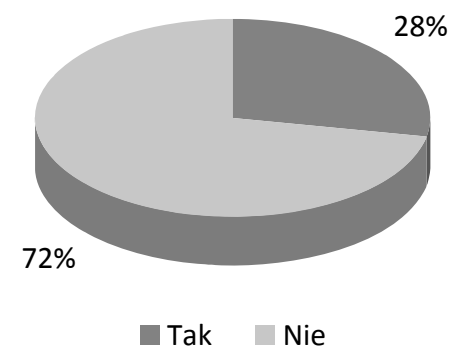

Rycina 5. Zdiagnozowane wcześniej schorzenia układu krążenia wśród badanych

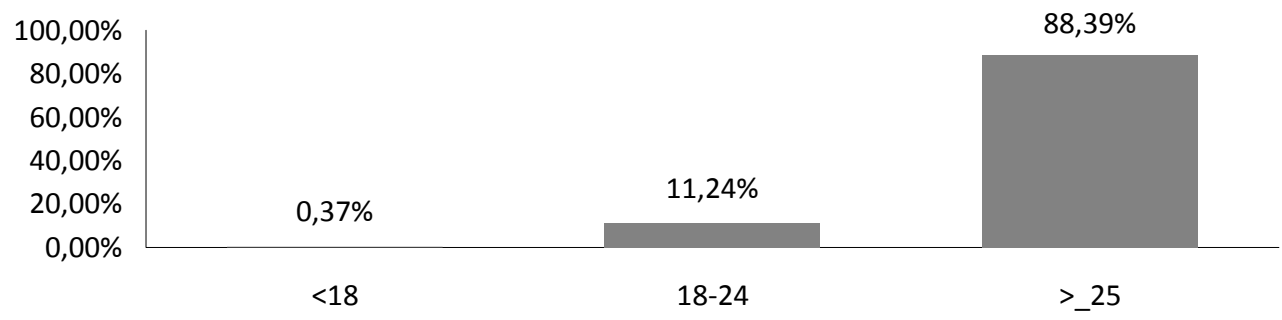

Rycina 4. Wskaźnik BMI badanych

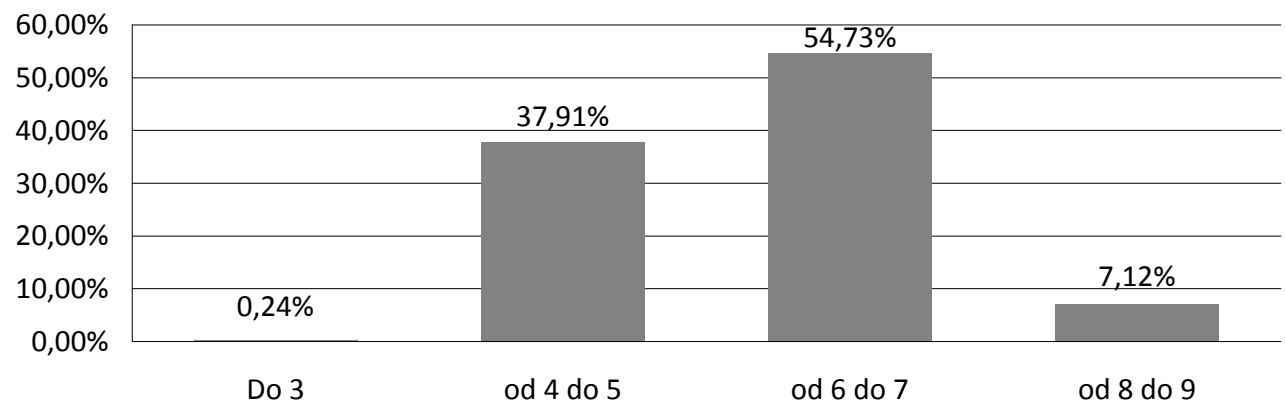

Rycina 6. Liczba czynników ryzyka wystąpienia chorób układu krążenia wśród badanych 


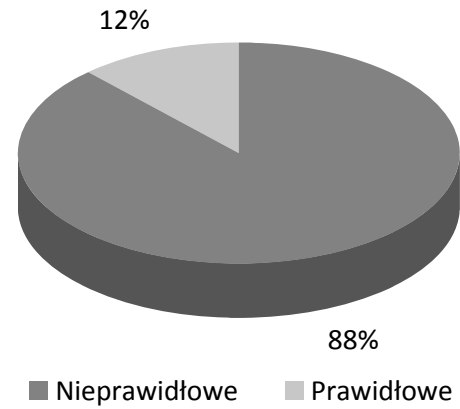

Rycina 7. Wyniki badań analitycznych wśród badanych

W badaniu echokardiograficznym nieprawidłowe wyniki stanowiły 55\% ogółu. Lekarze zwracali przy tym uwagę głównie na takie problemy, jak przerost koncentrycznych mięśnia lewej komory, powiększoną jamę lewego przedsionka, łagodną niedomykalność zastawki trójdzielnej, zaburzenia relacji mięśnia lewej komory czy też zaburzenia relaksacji mięśnia lewej komory (ryc. 8).

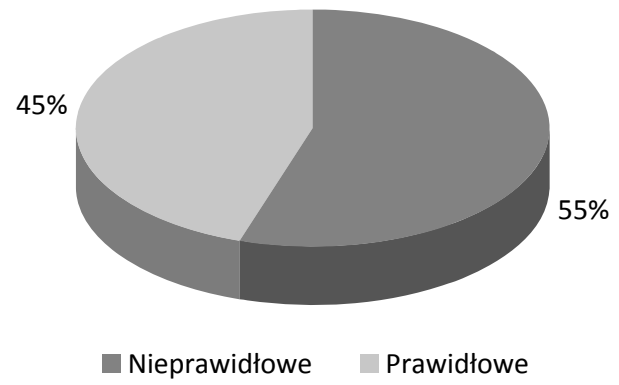

Rycina 8. Wyniki badań echokardiograficznych wśród badanych
W ramach rozpoznania, lekarze uczestniczacy $\mathrm{w}$ projekcie wskazali przede wszystkim na problem nadciśnienia, który występował u ponad połowy uczestników badania $(55,13 \%)$. Drugim z problemów (pod względem powszechności jego występowania) okazał się być problem nadwagi i otyłości. Zgodnie z wynikami badań, problem ten dotyczy blisko $22 \%$ badanych (ryc. 9).

System SCORE służy do szacowania indywidualnego ryzyka zgonu z powodu incydentu sercowo -naczyniowego (takiego jak zawał serca, udar mózgu, pęknięcie tętniaka aorty) w ciągu następnych 10 lat, w oparciu o czynniki ryzyka występujące u danej osoby. Wyodrębniono cztery kategorie ryzyka sercowo-naczyniowego: niskie (poniżej 1\%), umiarkowane (od 1 do 4\%), zwiększone (od 5 do 9\%), znaczenie zwiększone (10\% i więcej).

Aż blisko $60 \%$ osób poddanych badaniu uzyskało wynik w zakresie 1-4\%, co stanowi o umiarkowanym ryzyku sercowo - naczyniowym. Pozostała część przypadła głównie na przedział 5-9\% (21,13\%), świadcząca o zwiększonym ryzyku w tym zakresie. Aż 12,41 \% osób znalazło się w przedziale $10 \%$ i więcej, co stanowi o znacznie zwiększonym ryzyku. Pozostała część $(6,78 \%)$ przypada na osoby, których wyniki stanowi poniżej 1\% (niskie ryzyko) (ryc. 10).

\section{Dyskusja}

Jednym z najbardziej rozpowszechnionych czynników ryzyka sercowo - naczyniowego jest nadciśnienie tętnicze (Zdrojewski, 2015; Ndumel, Baer, Shaykevich, 2012). W badanej populacji nadciśnie-

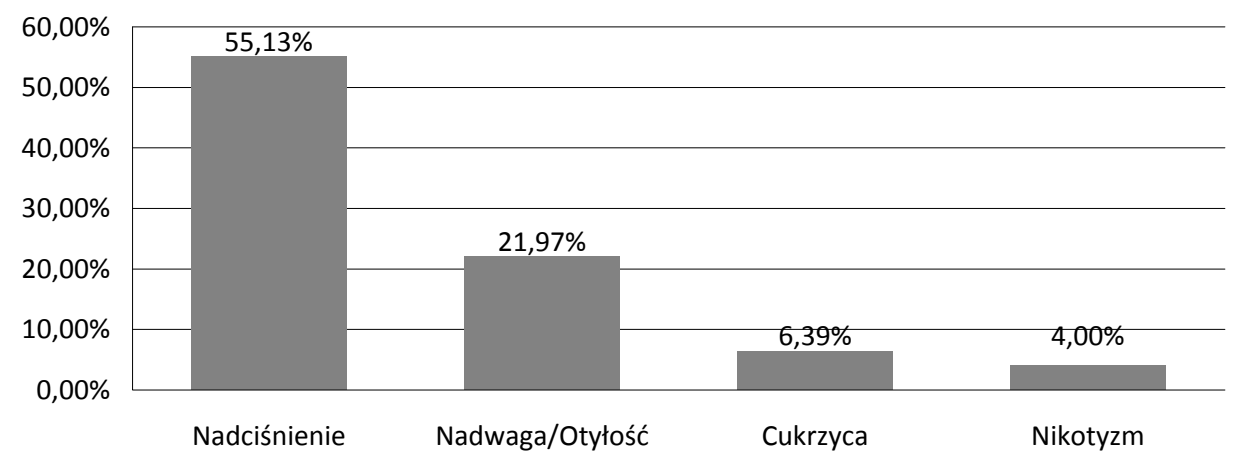

Rycina 9. Rozpoznanie - najczęściej występujące czynniki ryzyka

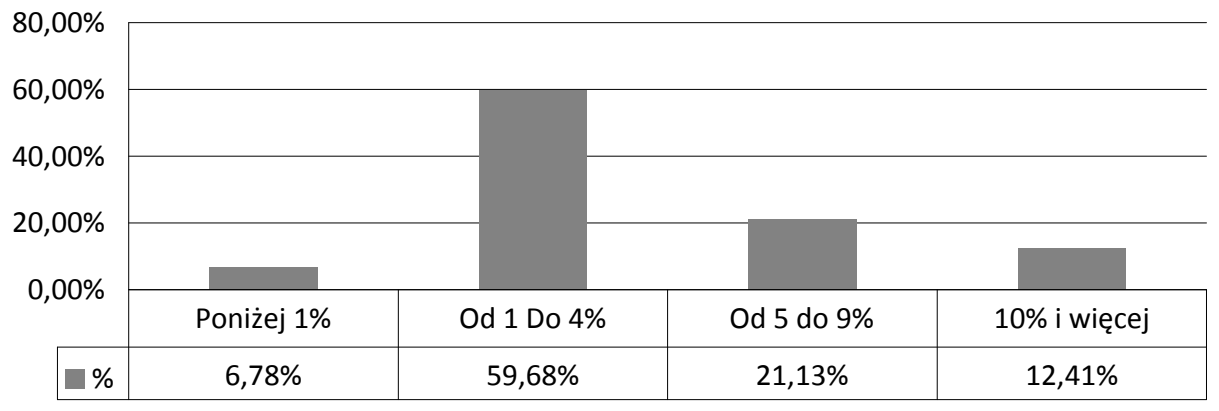

Rycina 10. Ryzyko incydentu sercowo-naczyniowego badanych wg algorytmu SCORE 
nie tętnicze stwierdzono u 55,13\% badanych. Wyższy odsetek chorych z nadciśnieniem stwierdziła w swojej pracy Sulicka i wsp.: dla całej populacji w wieku od 14 do 102 lat odsetek chorych z nadciśnieniem wyniósł 74,0\% (Sulicka i in., 2006).

W badaniu nadwagę rozpoznano u $21,97 \%$ badanych, natomiast średnia wartość BMI wyniosła 22,6 $\mathrm{kg} / \mathrm{m} 2$. W badaniu Sulickiej i wsp. obejmującym, populację 61 tys. populację uzyskano wartość BMI - 27,5 kg/m2 (Sulicka i in., 2006).

Światowe dane odnoszące się co do rozpowszechnienia cukrzycy typu 2 informują o 5 - 7\% ogółu populacji. Rzeczywista liczba chorych może być jednak znacznie wyższa, ponieważ w wielu krajach, szczególnie w tych o niższym statusie ekonomicznym, nie są regularnie przeprowadzane badania epidemiologiczne. Poza tym, podawane dane opierają się na innych kryteriach rozpoznania tej choroby, które w znacznej mierze ulegały zmianie na przestrzeni lat. Polska w porównaniu z innymi krajami jest oceniana jako państwo o umiarkowanej chorobowości z powodu cukrzycy, jednak tak jak w innych krajach chorobowość ta stale wzrasta (Jermendy i in., 2010; Puddu, Menotti, Tolonen, 2011). W badanej populacji cukrzycę stwierdzono w 6,39\% przypadków. Z kolei Jermendy i wsp. przeprowadzili na Węgrzech badanie, które objęło 1803 pacjentów w wieku 20-69 lat. Odsetek pacjentów leczonych $\mathrm{z}$ powodu cukrzycy był nieco wyższy (7,21 vs 6,39\%) (Jermendy i in., 2010). Interesujące spostrzeżenia poczyniono $\mathrm{w}$ ramach programu MAYDIA, który badał populację zamieszkałą na wyspie Mayotte. Cukrzycę zdiagnozowano tam u $10,5 \%$ populacji, w tym $26 \%$ badanych znajdowało się w wieku 60 - 69 lat. Prawie połowa pacjentów do momentu badania nie zdawała sobie sprawy, że choruje na cukrzyce (Solet, Baroux, Pochet, 2011; Spigt, Rikkers, Doornbos, 2009).

Palenie tytoniu jest bardzo istotnym czynnikiem ryzyka chorób układu krążenia, a równocześnie czynnikiem teoretycznie modyfikowalnym w największym stopniu. W niniejszym badaniu palenie tytoniu zadeklarowało 4,00\% badanych, Wyższe wartości niż w grupie badanych notuje się w Ameryce Północnej. Według danych uzyskanych z programu National Health and Nutrition Survey 2005
- 2008 w USA w wieku 45-64 lata łączny procent palaczy wyniósł 21,1\% (Conroy i in., 2003; Maniecka-Bryła, Maciak, Kowalska, 2008; Polakowska, Piotrowski, Tykarski, 2005).

Ocena aktywności fizycznej na ogół opiera się na informacjach pozyskanych z wywiadu. W grupie badanych odsetek pacjentów, którzy poświęcali na aktywność fizyczną co najmniej 90 minut tygodniowo wyniósł $22 \%$. W badaniu Murphy i wsp. w ramach programu Northern Ireland Sport and Physical Activity Survey, zrealizowanego w Irlandii Północnej procent osób deklarujących aktywność fizyczną co najmniej 150 minut tygodniowo wynosiła od 55\% dla populacji w wieku 31-40 lat do 41\% dla grupy 51-60 lat (Murphy, Donnelly, Shibli, 2012).

W badaniu do grupy o niskim ryzyku zgonu z powodu chorób układu krążenia zostało zakwalifikowanych $6,78 \%$ badanych, do grupy umiarkowanego ryzyka $59,68 \%$ badanych, natomiast do grupy wysokiego ryzyka 33,54\% pacjentów. W badaniu Bunescu i wsp. obejmującym 801 pacjentów do grupy wysokiego ryzyka zaliczono 39,2\% badanych (Bunescu, Stoffers, van den Akker, 2008; Dorobantu, Badila, Ghiorghe, 2008).

\section{Wnioski}

1. Stwierdzono istnienie czynników w istotny sposób mogących wpływać na choroby układu krążenia: waga, nadciśnienie tętnicze, brak aktywność fizycznej.

2. Zbadano, iż blisko 60\% osób biorących udział w projekcie znajdowało się w umiarkowanej grupie ryzyka zgonu z powodu incydentu sercowo-naczyniowego.

3. Najczęstszym zaleceniem lekarzy pracujących w poradniach POZ była kontrola w poradni kardiologicznej. Zalecenie to dotyczyło ponad 27\% ogółu badanych.

4. Badania wskazują na konieczność intensyfikacji działań zmierzających do wczesnego wykrywania osób zagrożonych czynnikami ryzyka choroby niedokrwiennej serca oraz poprawy skuteczności postępowania profilaktycznego.

\section{Literatura:}

1. Bunescu, D.M., Stoffers, H.E., van den Akker, M, Dinant, G.J. (2008). Coronary heart disease and cardiovascular risk factors among people aged $25-65$ years, as seen in Romanian primary healthcare. Eur. J. Gen. Pract., 14(2), 56-64. https://doi.org/10.1080/13814780802343141

2. Centers of Disease Control and Prevention. Vital signs: Prevalence, treatment and control of hypertension - United States - 1999 - 2002 and 2005 - 2008. Pobrane z: www.cdc.gov.mmwr

3. Conroy, R., Pyorala, K., Fitzgerald, A., (2003). Estimation of ten-year risk of fatal cardiovascular disease in Europe: the SCORE project. Eur. Heart J., 24(11), 987-1003. https://doi.org/10.1016/s0195-668x(03)00114-3

4. Dorobantu, M., Badila, E., Ghiorghe, S., Darabont, R.O., Olteanu, M., Flondor, P. (2008). Total cardiovascular risk estimation in Romania. Data from the SEPHAR study. Rom. J. Intern. Med., 46(1), 29-37.

5. Perk, J., De Backer, G., Gohlke, H., Graham, I., Reiner, Z., Verschuren, M., Albus, C., Benlian, P., Boysen, G., Cifkova, R., Deaton, C., Ebrahim, S., Fisher, M., Germano, G., Hobbs, R., Hoes, A., Karadeniz, S., Mezzani, 
A., Prescott, E., Ryden, L., Scherer, M., Syvänne, M., Scholte op Reimer, W.J., Vrints, C., Wood, D., Zamorano, J.L., Zannad, F., European Association for Cardiovascular Prevention \& Rehabilitation (EACPR); ESC Committee for Practice Guidelines (CPG). (2012). European Guidelines on cardiovascular disease prevention in clinical practice (version 2012). The Fifth Joint Task Force of the European Society of Cardiology and Other Societies on Cardiovascular Disease Prevention in Clinical Practice (constituted by representatives of nine societies and by invited experts). Eur Heart J., 33(13): 1635-1701. https://doi.org/10.1093/eurheartj/ehs092

6. Jermendy, G., Nadas, J., Szigethy, E., Szeles, G., Nagy, A., Hidwegi, T., Paragh, G., Adany, R. (2010). Prevalence rate of diabetes mellitus and impaired fasting glycaemia in Hungary: cross - sectional study on nationally representative sample of people aged 20 - 69 years. Croat. Med J., 51(2), 151-156. https://doi.org/10.3325/cmj.2010.51.151

7. Korzeniowska-Ginter, R., Komorowska-Szczepańska, W., Stasiak-Szelągiewicz, E. (2013). Nutritional preferences of patients with cardiovascular diseases. Family Medicine \& Primary Care Review, 15(2), $124-126$.

8. Kosobudzki, M., Bortkiewicz, A. (2012). Genetic determinants of cardiovascular diseases. Forum Medycyny Rodzinnej, 6(1), 1-13.

9. Maniecka-Bryła, I., Maciak, A., Kowalska, A. (2008). Palenie tytoniu w wieku 35 - 55 lat w wybranej próbie mieszkańców miasta średniej wielkości. Przegl. Lek., 65(10), 612 - 616.

10. Murphy, M.H., Donnelly, P., Shibli, S., Foster, C., Nevill, A.M. (2012). Physical Activity, walking and leannes: Ananalysis of the Northern Ireland Sport and Physical Activty Survey. Prev. Med., 54(2), 140-144. https://doi.org/10.1016/j.ypmed.2011.12.008

11. Ndumele, C.D., Baer, H.J., Shaykevich, S, Lipsitz, S.R., Hicks, L.S. (2012). Cardiovascular Disease and Risk in Primary Care Settings in the United States. Am. J. Cardiol., 109(4), 521-526. https://doi.org/10.1016/j.amjcard.2011.09.047

12. Polakowska, M., Piotrowski, W., Tykarski, A. (2005). Nałóg palenia tytoniu w populacji polskiej. Wyniki programu WOBASZ. Kardiol. Pol., 63(6) (supl. 4), 626-631.

13. Puddu, P.E., Menotti, A, Tolonen, H, Nedeljkovic, S, Kafatos, A.G. (2011). Determinants of 40-year allcause mortality in the European cohorts of the Seven Countries Study. Eur. J. Epidemiol., 26(8), 595-608. https://doi.org/10.1007/s10654-011-9600-7

14. Rodriguez-leyva, D., Mccullough, R., Pierce, G. (2009). Nutrition as a vehicle for cardiovascular translational research.J Cardiovasc Trans Res, 2(3), 328-334. https://doi.org/10.1007/s12265-009-9116-7

15. Sieradzki, J., Wilkins, A., Szczepański, M. (2005). SCREEN-POL 2 - aktywne wyszukiwanie i wczesne rozpoznanie cukrzycy typu 2 u pacjentów zgłaszających się do lekarzy podstawowej opieki zdrowotnej w Polsce. Wyniki ogólnopolskiego, wieloośrodkowego programu przesiewowego. Diabetologia Praktyczna, 3, 103-114.

16. Solet, J.L., Baroux, N., Pochet, M., (2011). Prevalence of diabetes mellitus and other cardiovascular risk factors in Mayotte in 2008: the MAYDIA Study. Diabetes Metab., 37(3), 201-217. https://doi.org/10.1016/j.diabet.2010.09.007

17. Spigt, M., Rikkers, A., Doornbos, M., Wouters, E., Spitz, I., Van Amelsvoort, L., Zwietering, P. (2009). The effect of screening on the prevalence of diagnosed type 2 diabetes in primary care. Scand. J. Prim. Health Care, 24(4), 232-237. https://doi.org/10.3109/02813430903226480

18. Sulicka, J., Fornal, M., Gryglewska, B., Wizner, B., Cwynar, M., Grodzicki, T. (2006). Wybrane czynniki ryzyka chorób sercowo-naczyniowych u pacjentów podstawowej opieki zdrowotnej. Nadciśnienie Tętnicze, 5, 370-376. https://doi.org/10.1080/08037050902903447

19. Szczęch, R., Narkiewicz, K. (2008). Czynniki ryzyka chorób układu krążenia. Materiały Informacyjne Dla Pacjentów. Choroby Serca i Naczyń, 5(1), 55-56.

20. Zdrojewski, T., Jankowski, P., Hoffman, P., Bandosz, P., Bartuś, S., Chwojnicki, K., Drygas, W., Gaciong, Z., Kalarus, Z., Kaźmierczak, J., Kopeć, G., Mamcarz, A., Opolski, G., Pająk, A., Piotrowicz R., Podolec, P., Rutkowski, M., Rynkiewicz, A., Siwińska, A., Stępińska, J., Windak, A., Wojtyniak, B. (2015). A new version of cardiovascular risk assessment system and risk charts calibrated for Polish population. Kardiologia Polska, 73(10), 958-961. https://doi.org/10.5603/kp.2015.0182 